\title{
Efficacy of antidepressants in treating the negative symptoms of chronic schizophrenia: meta-analysis
}

Surendra P. Singh, Vidhi Singh, Nilamadhab Kar and Kelvin Chan

\section{Background}

Treatment of negative symptoms in chronic schizophrenia continues to be a major clinical issue.

\section{Aims}

To analyse the efficacy of add-on antidepressants for the treatment of negative symptoms of chronic schizophrenia.

\section{Method}

Systematic review and meta-analysis of randomised controlled trials comparing the effect of antidepressants and placebo on the negative symptoms of chronic schizophrenia, measured through standardised rating scales. Outcome was measured as standardised mean difference between end-of-trial and baseline scores of negative symptoms

\section{Results}

There were 23 trials from 22 publications $(n=819)$. The antidepressants involved were selective serotonin reuptake inhibitors, mirtazapine, reboxetine, mianserin, trazodone and ritanserin; trials on other antidepressants were not available. The overall standardised mean difference was moderate $(-0.48)$ in favour of antidepressants and subgroup analysis revealed significant responses for fluoxetine, trazodone and ritanserin.

\section{Conclusions}

Antidepressants along with antipsychotics are more effective in treating the negative symptoms of schizophrenia than antipsychotics alone.

\section{Declaration of interest}

None.
Negative symptoms constitute a key element of schizophrenia and affect individuals' ability to cope with everyday activities and have a negative impact on their quality of life. ${ }^{1}$ Treatment of negative and resistant ${ }^{2}$ symptoms in chronic schizophrenia continues to remain a major clinical hurdle, in spite of the introduction of atypical antipsychotics. Antidepressants have been a natural and common choice for the treatment of negative symptoms considering the conceptual proximity of their mode of action and the aetiological hypotheses involving related neurotransmitters. ${ }^{3}$ Many reports are currently available involving trials of antidepressants in treating the negative symptoms of schizophrenia. There have been mostly positive outcomes regarding the effectiveness, however there are reports of negative findings as well. ${ }^{4-6}$ We therefore wanted to review and analyse the efficacy of antidepressants in treating negative symptoms of chronic schizophrenia. We also aimed to explore the influence of clinical factors like the individual's age, age at onset, duration of illness, dose of antipsychotic medications, baseline severity of positive and negative symptoms, duration of trial, and gender differences on the responsiveness of add-on antidepressant medications.

\section{Method}

\section{Data source and study selection}

All randomised controlled trials on schizophrenia using drug interventions were searched on 10 August 2009 in titles and abstracts of databases from PubMed, Cochrane Library, EMBASE, CINAHL, and PsycINFO. For PubMed the advanced search criteria were as follows: (Antidepressive Agents [Pharmacological Action] AND Schizophrenia [MeSH]) Limits: Humans, Clinical Trial, Randomized Controlled Trial, Clinical Trial, Phase I, Clinical Trial, Phase II, Clinical Trial, Phase III, Clinical Trial, Phase IV, Controlled Clinical Trial.

The search retrieved 455 publications, which were progressively subjected to further electronic search for non-case-sensitive relevant words in their title, abstract or keywords and then manual validation. A search for the word 'blind' generated 189 records, the word 'double' filtered 183 records, and the word 'placebo' rendered a list of 100 records. This list of 100 publications went through detailed manual scanning of their titles, abstracts and keywords to determine their suitability for this review. Trials were excluded if an antidepressant was used to treat an explicit comorbid psychiatric disorder, for example postpsychotic depression, obsessive-compulsive disorder, emergence of major depression in remitted schizophrenia; or if an antidepressant was not used as add-on medication; or if medications used were not normally classified under a standard antidepressant category, for example tryptophan, des-tyrosine, sibutramine, lithium, apomorphine and bupropion. The inclusion criteria were application of robust diagnostic methodology, sample randomisation, double-blind assessments, and comparison with a placebo control group. Publications with ambiguity were not excluded without checking the articles in full.

The above procedure resulted into selection of 29 publications requiring further detailed screening. The studies were also supposed to meet the diagnostic criteria of chronicity defined as duration of illness of more than 2 years. Three publications ${ }^{7-9}$ were excluded as chronicity of illness was not known and another one $^{10}$ was excluded as it did not have a placebo control group. The main authors of other two studies ${ }^{11,12}$ could be successfully contacted and it was confirmed that almost all patients had chronic illness. We included articles if they had used standardised tools like the Scale for the Assessment of Negative Symptoms (SANS), Positive and Negative Syndrome Scale (PANSS) and the Brief Psychiatric Rating Scale (BPRS) to measure change in negative symptoms. This criterion led to exclusion of three more trials. ${ }^{13-15}$ The final selection list consisted of 22 publications ${ }^{5,6,11,12,16-33}$ providing comparison of 23 add-on antidepressant interventions with placebo. This whole process was jointly undertaken by two authors (S.P.S. and N.K.) with the option to consult the third author (K.C.) to resolve conflicts and ambiguities.

\section{Data extraction}

The data-sets extracted for each study and their interrelationship are shown in Fig 1. The $\mathrm{R}$ statistical software (Version 2.9.0) 


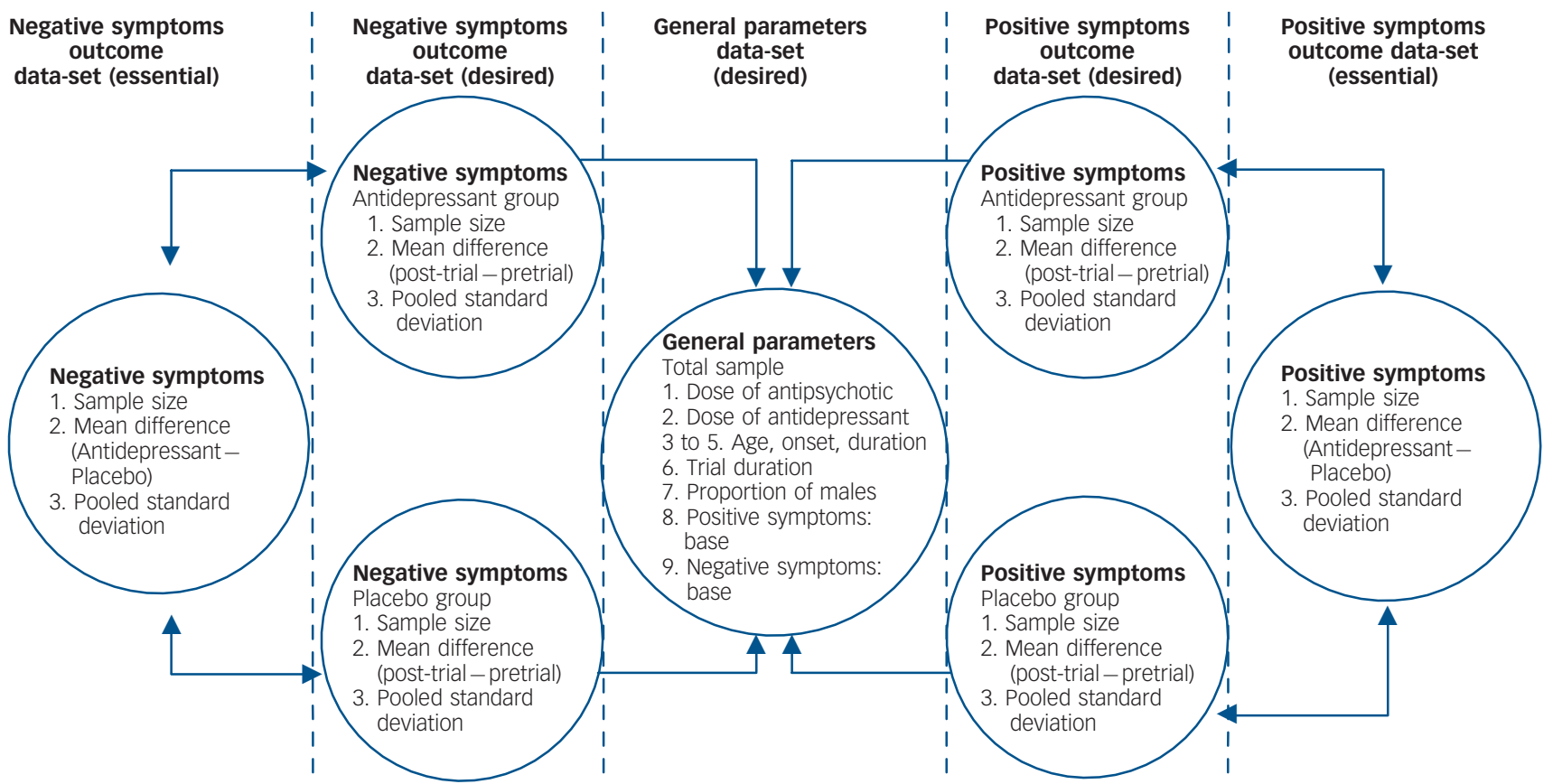

Fig. 1 Data-sets for studies on negative symptoms of chronic schizophrenia.

(R Foundation for Statistical Computing, Vienna, Austria; see http:// www.r-project.org) and its meta package (http://cran.r-project. org/web/package/meta) were used for statistical analysis. The MiMa module (Version 1.4; see http://www.wvbauer.com) and the MICE imputation package (Version 1.4; http://cran.r-project. org/web/packages/mice/index.html) available in $\mathrm{R}$ programming language were used respectively for meta-regression and imputation. The programming codes for enhanced and structured graphic output were written in $\mathrm{R}$ language by one of the author (V.S.). All programs were run on a Linux (Ubuntu 9.04).

The difference between end-of-trial and baseline mean scores and its standard deviation on negative symptoms rating scales individually in each arms of the experimental and control groups were the minimum data-set necessary for computation of the effect size. All these data were either available or could be calculated from published results (online Appendix DS1). Calibrated values were obtained from the illustrated graphs for baseline severity in one study ${ }^{32}$ and for pre- and post-trial scores in two trials. ${ }^{5,17}$ In the absence of a fixed-dosing schedule, the mean or median of the titrated or flexible dose regime was used to calculate the baseline dose of antipsychotic medication. This dose was converted to equivalent daily defined dose (DDD) applying World Health Organization criteria. ${ }^{34}$

There were missing data for baseline severity of negative symptoms in three trials, ${ }^{17,25,32}$ severity of positive symptoms in four trials, ${ }^{18,22,25,32}$ proportion of males and their age in two studies, ${ }^{5,17}$ and onset and duration of illness in five studies. ${ }^{5,11,12,17,19}$ These values were obtained using imputation. None of these values were related to measurement of effect size.

\section{Data synthesis}

Data from only one of the scales was used for statistical analysis if researchers of a study used more than one rating scale to quantify negative symptoms. In this situation, order of preference was total scores on SANS followed by scores on the negative symptom subscale of PANSS and then the negative symptom subscale of the BPRS. Weighted mean and standardised weighted mean
(SWM) were calculated as in Appendix DS1. The SWM from the means and standard deviation of baseline negative symptoms for the total sample of a study was treated as the baseline severity of negative symptoms. The baseline severity of positive symptoms was computed in a similar manner. Similar to the approach adopted by others, ${ }^{35}$ a default value of Pearson's correlation coefficient of $r=0.5$ was taken as the covariance for repeated measures to calculate the pooled standard deviation for both the control and experimental groups (Appendix DS1, Equation 3). For the non-dependent data-set, the process is defined in Equation 6 (Appendix DS1). The outcome for each study was defined in terms of the standardised mean difference (SMD), which is the difference in improvement between the drug and the placebo group divided by their pooled standard deviation. Using the meta-analysis software package, the negative symptoms outcome data-sets (Fig. 1) were utilised to calculate the SMDs of the primary outcome measure between drug and placebo groups. This primary outcome measure for each study with its variance as dependent variables was used for meta-regression with the general parameter data-set (Fig. 1) as independent variables. Heterogeneity in the regression was measured using the restricted maximum likehood; the default value for the Fisher scoring algorithm was 0.00001; maximum number of iteration was set to 1000 , width of confidence interval for an individual parameter was set to 0.05 to yield a $95 \%$ confidence interval and rounding of decimal numbers was set to four digits.

\section{Results}

The general characteristics of the studies included are given in Table 1. The overall sample size was 819 , which was approximately equally divided between the experimental $(n=416)$ and control $(n=403)$ groups. Most participants were receiving nearly twice the average dose of antipsychotic medications. The average duration of illness was over 15 years with onset in early adulthood; and there was preponderance of negative symptoms over positive symptoms. The trial periods ranged between 4 and 12 weeks. 


\begin{tabular}{|c|c|c|c|c|c|c|c|c|c|}
\hline Authors & Year & Base & Drug & $\begin{array}{c}\text { Trial, } \\
\text { weeks }\end{array}$ & $\begin{array}{l}\text { Age at } \\
\text { study } \\
\text { entry, } \\
\text { years }\end{array}$ & $\begin{array}{c}\text { Duration } \\
\text { of } \\
\text { illness, } \\
\text { years }\end{array}$ & $\begin{array}{c}\text { Males, } \\
\text { proportion }\end{array}$ & $\begin{array}{l}\text { Severity } \\
\text { of } \\
\text { negative } \\
\text { symptoms }\end{array}$ & $\begin{array}{l}\text { Severity } \\
\text { of } \\
\text { positive } \\
\text { symptoms }\end{array}$ \\
\hline Salokangas et $a l^{5}$ & 1996 & Antipsychotic & Citalopram & 12 & 41 & 16 & 0.64 & 0.65 & 0.64 \\
\hline Arango et $a^{23}$ & 2000 & Antipsychotic & Fluoxetine & 8 & 37 & 7 & 0.72 & 0.65 & 0.64 \\
\hline Buchanan et $a l^{21}$ & 1996 & Clozapine & Fluoxetine & 8 & 35 & 16 & 0.70 & 0.66 & 0.67 \\
\hline Goff et $a^{20}$ & 1995 & Antipsychotic & Fluoxetine & 6 & 43 & 20 & 0.88 & 0.68 & 0.67 \\
\hline Spina et $a l^{19}$ & 1994 & Antipsychotic & Fluoxetine & 12 & 46 & 16 & 0.68 & 0.69 & 0.65 \\
\hline Silver \& Nassar ${ }^{16}$ & 1992 & Antipsychotic & Fluvoxamine & 7 & 42 & 18 & 0.63 & 0.68 & 0.38 \\
\hline Silver et $a^{24}$ & 2000 & Antipsychotic & Fluvoxamine & 6 & 43 & 20 & 0.23 & 0.69 & 0.67 \\
\hline Hayashi et al ${ }^{22}$ & 1997 & Antipsychotic & Mianserin & 5 & 62 & 34 & 0.59 & 0.68 & 0.64 \\
\hline Poyurovsky et $a^{28}$ & 2003 & Antipsychotic & Mianserin & 4 & 44 & 17 & 0.71 & 0.69 & 0.53 \\
\hline Shiloh et $a{ }^{26}$ & 2002 & Antipsychotic & Mianserin & 6 & 38 & 12 & 0.61 & 0.66 & 0.68 \\
\hline Berk et $a l^{11}$ & 2001 & Haloperidol & Mirtazapine & 6 & 30 & 16 & 0.83 & 0.68 & 0.66 \\
\hline Berk et al ${ }^{12}$ & 2009 & Antipsychotic & Mirtazapine & 6 & 37 & 16 & 0.84 & 0.69 & 0.67 \\
\hline Joffe et $a{ }^{\beta 3}$ & 2009 & Antipsychotic & Mirtazapine & 6 & 46 & 22 & 0.51 & 0.69 & 0.69 \\
\hline Zocali et a/29 & 2004 & Clozapine & Mirtazapine & 8 & 32 & 12 & 0.63 & 0.69 & 0.66 \\
\hline Jockers-Scherubl et $a l^{30}$ & 2005 & Antipsychotic & Paroxetine & 12 & 40 & 10 & 0.48 & 0.69 & 0.68 \\
\hline Poyurovsky et $a l^{27}$ & 2003 & Olanzapine & Reboxetine & 6 & 31 & 6 & 0.65 & 0.67 & 0.64 \\
\hline Poyurovsky et $\left.a\right|^{31}$ & 2007 & Olanzapine & Reboxetine & 6 & 30 & 4 & 0.64 & 0.69 & 0.67 \\
\hline Schutz \& Berk ${ }^{25}$ & 2001 & Haloperidol & Reboxetine & 6 & 33 & 8 & 0.93 & 0.68 & 0.64 \\
\hline Akhondzadeh et $a^{\beta 2}$ & 2008 & Risperidone & Ritanserin & 8 & 41 & 16 & 0.63 & 0.68 & 0.64 \\
\hline Duinkerke et al ${ }^{17}$ & 1993 & Antipsychotic & Ritanserin & 6 & 41 & 16 & 0.64 & 0.68 & 0.64 \\
\hline Lee et $a l^{6}$ & 1998 & Haloperidol & Sertraline & 8 & 40 & 10 & 0.56 & 0.68 & 0.68 \\
\hline Decina et $a l^{18}$ & 1994 & Antipsychotic & Trazodone & 6 & 56 & 24 & 0.49 & 0.68 & 0.64 \\
\hline Hayashi et al22 & 1997 & Antipsychotic & Trazodone & 5 & 62 & 34 & 0.59 & 0.68 & 0.64 \\
\hline
\end{tabular}

The effect size and related parameters along with equivalent odd ratios (OR) and the applicable effects model are displayed in online Table DS1. As standard practice, a fixed-effects model was used for homogeneous studies and a random-effects model for heterogeneous studies. Applying the random-effects model $(Q=54.27$, d.f. $=22, \quad P<0.05)$ antidepressants as an add-on therapy to antipsychotic medications in chronic schizophrenia seem to have a desirable effect of medium size (SMD $=-0.48$ ) for negative symptoms. The SMDs of three studies ${ }^{19,24,29}$ with very large effect sizes can be treated as outliers. Figure 2 displays the summary result of all the studies. There was no single study effect size that indicated worsening of negative symptoms from use of any individual antidepressant. No study on citalopram, mianserin, reboxetine or sertraline reported improvement in negative symptoms.

\section{Subgroup analyses}

For the subgroup analysis, we focused on medications that had a minimum of two trials and a sample size of 60 or more. The trials on fluoxetine, trazodone and ritanserin showed a statistically significant effect size in favour of these drugs; and the trials on mirtazapine, reboxetine, mianserin, and fluvoxamine did not (online Table DS1).

Studies of fluoxetine (Fig. 3) showed a medium effect size $(\mathrm{SMD}=-0.42)$ in favour; however, three out of four trials in this group were negative. Although the sample size for trazodone $(n=38$, placebo $=34)$ was comparatively small (Fig. 4$)$, its effect size was considerably large ( $\mathrm{SMD}=-0.70)$. The overall effect size for ritanserin (Fig. 5) was also large $(\mathrm{SMD}=-0.83)$ and both its individual trials were showing results in favour, unlike trazodone.

\section{Number needed to treat}

Assuming a $10 \%$ spontaneous improvement in the control group in their negative symptoms, the number needed to treat $(\mathrm{NNT})^{36}$ for antidepressants was 10; however after controlling for publication bias this increased to 15 . The NNT for fluoxetine, trazodone and ritanserin were 11, 6 and 5 respectively.

\section{Sensitivity analysis}

The data were analysed to check the effect of publication bias using the 'trimfill' method. This led to the trimming of three trials, ${ }^{19,24,29}$ which reduced the overall SMD to -0.33 (95\% CI -0.59 to $-0.08, P<0.05)$ from -0.48 . We also estimated how the magnitude of assumed covariance between pre- and post-trial scores changed the effect size. The original estimates with $r=0.5$ produced an effect size of $\mathrm{SMD}=-0.48(95 \% \mathrm{CI}-0.71$ to $-0.25)$. Assuming a low correlation $(r=0.1)$ the effect size came down to $\mathrm{SMD}=-0.40(95 \% \mathrm{CI}-0.60$ to -0.21$)$; and with high correlation $(r=0.9)$, this increased to $\mathrm{SMD}=-0.74(95 \% \mathrm{CI}$ -1.10 to -0.39$)$.

\section{Association with moderators}

The study failed to find a significant association between nine moderators from the general parameter data-set (Fig. 1) with the outcome measure and its variance. A meta-regression test using the MiMa function found heterogeneity $(\mathrm{QE}=33.07$, d.f. $=13, P<0.05)$ among studies with a lack of significant influence $(\mathrm{QME}=9.93$, d.f. $=9, P>0.05)$ from moderators having an estimate of $0.03,-0.02,0.11,-0.3,0.19,0.07,0.05,-0.14$, and 0.24 respectively for dose of antidepressant, dose of antipsychotic medication, baseline severity of positive symptoms, baseline severity of negative symptoms, age at onset, duration of illness, duration of trial, age of individual and proportion of males in sample.

\section{Discussion}

This meta-analysis reviewed the effectiveness of antidepressants in the treatment of negative symptoms in chronic schizophrenia. Following a broad search in various databases we found 23 RCTs 


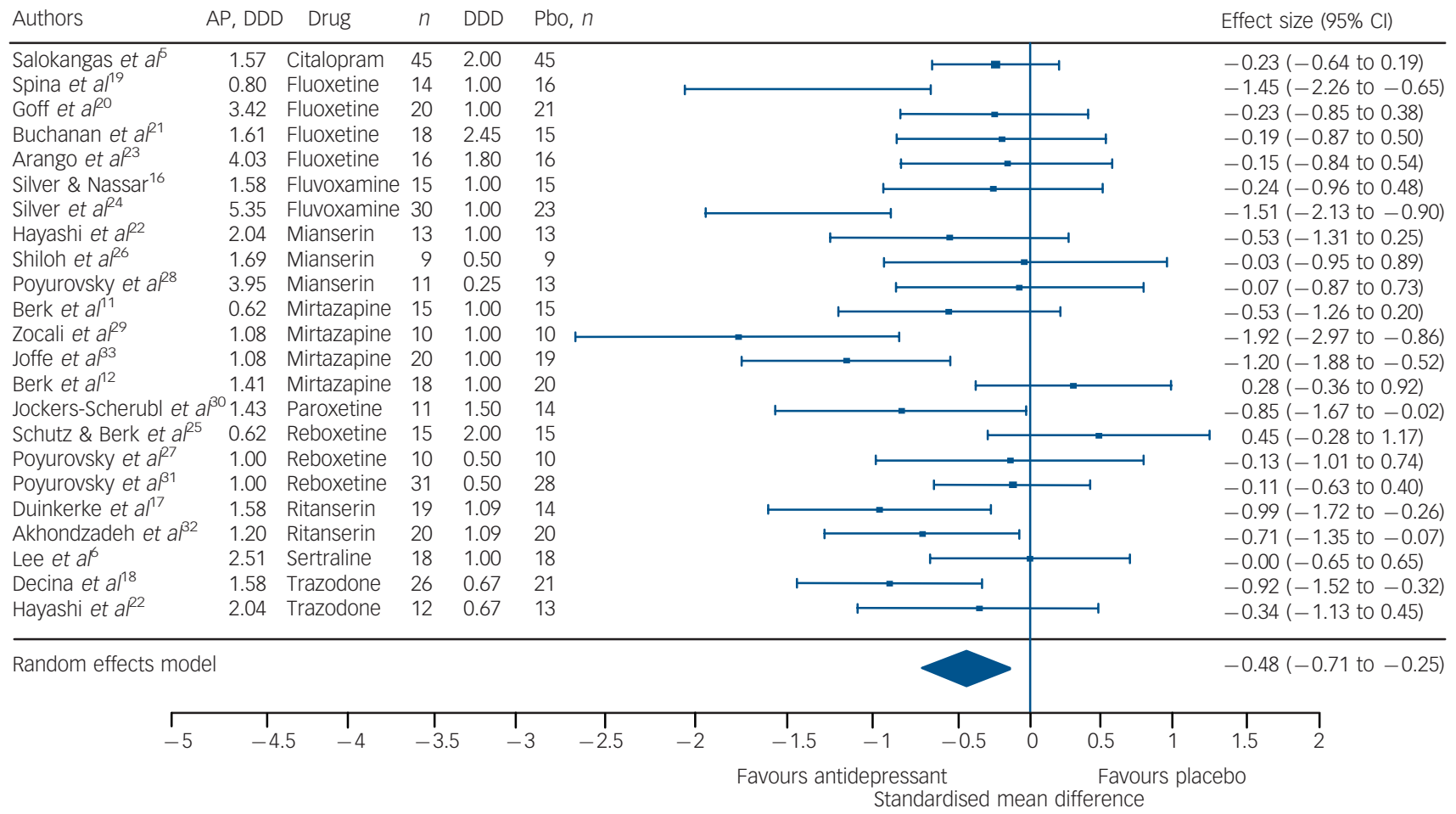

Fig. 2 Efficacy of antidepressants on negative symptoms of chronic schizophrenia (antidepressants total $n=416$; placebo total $n=403$ ).

AP, antipsychotic; DDD, daily defined dose; Pbo, placebo.

from 22 publications with an overall sample size of 819 for this meta-analysis. This is a fairly adequate sample size to reflect upon the treatment effects and it addresses some of the limitations and suggestions of previous studies ${ }^{37}$ of a similar nature. This review has included all published RCTs involving all antidepressants that included selective serotonin reuptake inhibitors (SSRI), mianserin, trazodone, mirtazapine, reboxetine and ritanserin. The overall results of this meta-analysis suggest that antidepressants as addon therapy to antipsychotic medications are significantly more effective than placebo in treating the negative symptoms of chronic schizophrenia.

\section{Efficacy of antidepressants for negative symptoms}

Using a random-effects model, (Fig. 2) the statistically significant overall effect size of -0.48 for usage of antidepressants can be considered as moderate applying Cohen's criteria. ${ }^{38}$ Even after trimfill analysis to control for publication bias the result was still significant, albeit with a reduced effect size $(\mathrm{SMD}=-0.33)$. This effect size is similar to the SMD for antidepressants in the treatment of primary depressive illness. ${ }^{39}$ Considering not only the statistical significance but also its clinical significance, ${ }^{40}$ antidepressant use for negative symptoms in chronic schizophrenia may appear justified. This review supports the observation from an earlier meta-analysis ${ }^{37}$ that showed a relatively larger effect size of SMD $=-0.71(95 \% \mathrm{CI}-1.09$ to -0.34$)$. The Cochrane review on this subject by Rummel et $a l^{41}$ also came to a similar conclusion (relative risk $(\mathrm{RR})=0.56,95 \%$ CI $0.32-0.97$ ) with a $20 \%$ improvement in negative symptoms. Similarly Sepehry et al reported a moderate and significant effect size when they re-analysed their data only including patients with chronic schizophrenia. ${ }^{42}$ The above observations suggest that antidepressants should be considered in the clinical management of negative symptoms, as additional symptom relief may lead to increased functionality and improved quality of life in individuals with chronic schizophrenia. It must be highlighted, however, that combination treatment has the potential concerns of an increased side-effect burden, unwanted drug interactions ${ }^{20}$ and resultant increased rates of non-adherence to treatment and higher cost. These issues require further study.

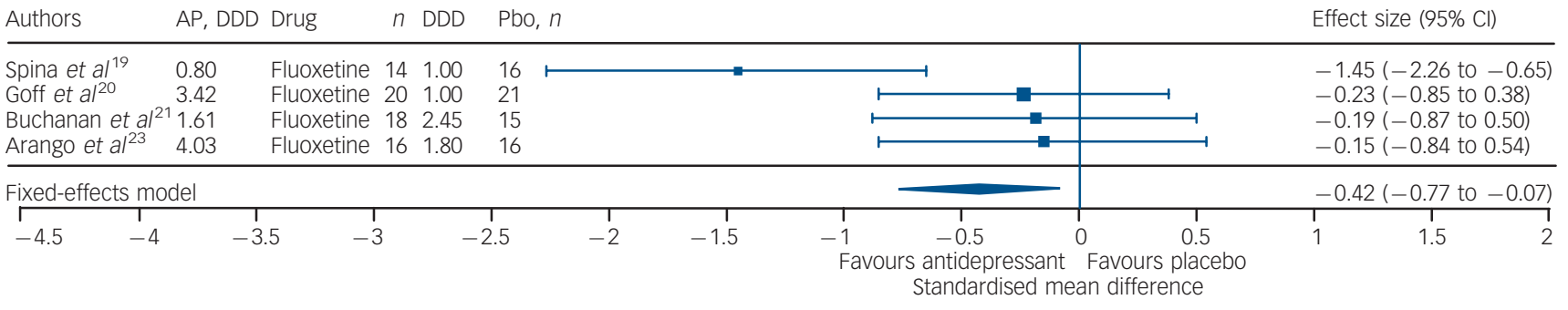

Fig. 3 Efficacy of fluoxetine on negative symptoms of chronic schizophrenia (fluoxetine total $n=68$; placebo total $n=68$ ). 


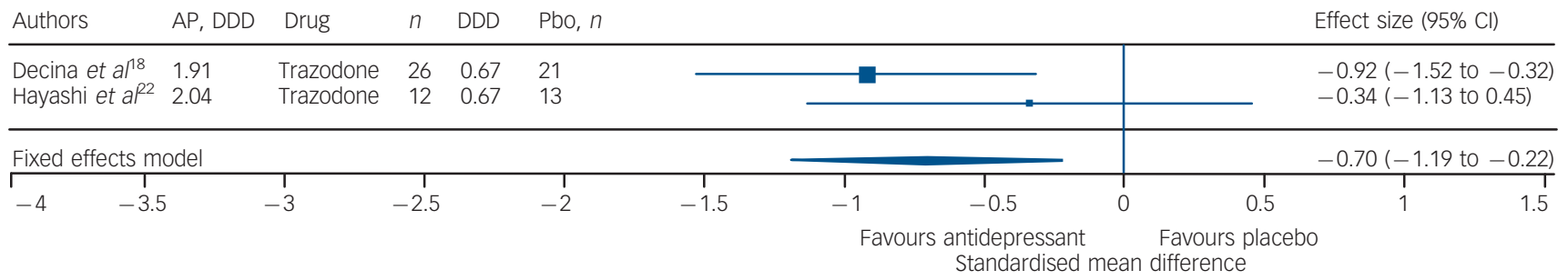

Fig. 4 Efficacy of trazodone on negative symptoms of chronic schizophrenia (trazodone total $n=38$; placebo (Pbo) total $n=34$ ).

AP, antipsychotic; DDD, daily defined dose; Pbo, placebo.

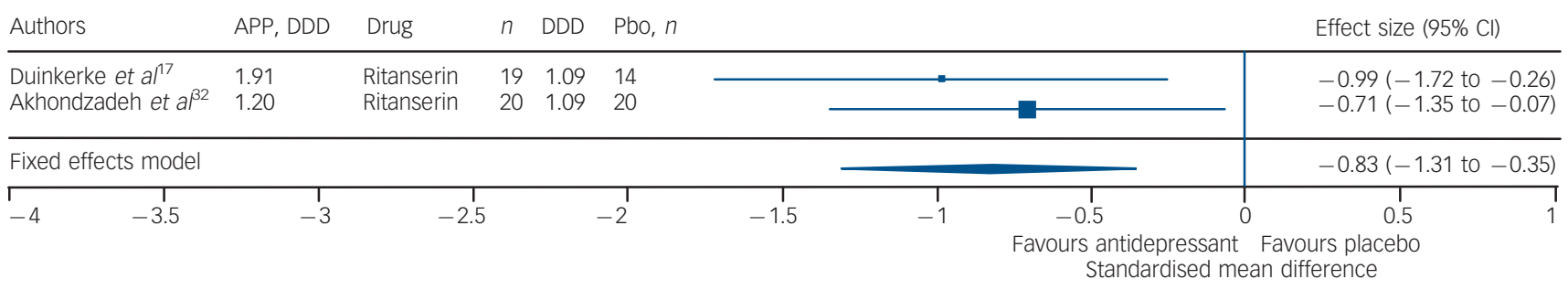

Fig. 5 Efficacy of ritanserin on negative symptoms of chronic schizophrenia (ritanserin total $n=39$; placebo (Pbo) total $n=34$ ).

AP, antipsychotic; DDD, daily defined dose; Pbo, placebo.

\section{Depression and negative symptoms}

The contribution of depression to negative symptoms is a possibility; and improvement of depression through antidepressant medications can influence the change in negative symptoms. It is a continuing debate whether the improvement is secondary to the reduction of depressive symptoms. ${ }^{37}$ All studies included in this meta-analysis used a standardised instrument for assessing negative symptoms, and change in scores following an intervention was based on ratings on the same scales. This primarily hopefully addresses the core issue of negative symptoms. The outcome, which does not appear to be secondary to other factors, suggests that probably this effect is independent of the antidepressant property.

\section{Individual antidepressants}

For individual antidepressants, the statistically significant effect size was in favour of fluoxetine, trazodone and ritanserin (in increasing order). Mirtazapine, reboxetine, mianserin, fluvoxamine, sertraline, paroxetine and citalopram did not seem to have a beneficial effect on negative symptoms. Owing to sample size limitation, especially in the context of a meta-analysis, there is a need for caution when interpreting the results for individual antidepressants.

It should be noted that three out of four trials involving fluoxetine were negative; and although the effect size was significant it was the lowest in comparison with that of trazodone and ritanserin. Studies using trazodone ${ }^{18,22}$ in conjunction with antipsychotics reported a reduction in the severity of negative symptoms in residual schizophrenia, especially 'affective flattening and blunting' and 'alogia', and that trazodone was safe and it did not exacerbate florid psychosis. ${ }^{18}$ Ritanserin, a $5-\mathrm{HT}_{2 \mathrm{c}}$ antagonist and classified as an antidepressant, has also been reported to have an additional intrinsic antidopaminergic effect, which has been suggested as the explanation for the reported improvement in negative symptoms of schizophrenia. ${ }^{43}$

The NNT of 10 for antidepressants as a group, 11 for fluoxetine, 6 for trazodone and 5 for ritanserin appear promising especially as these are for the negative symptoms of chronic schizophrenia. Compared with the reported NNT figures for antidepressants for depressive disorder, which vary considerably in different settings and studies ${ }^{44,45}$ from around 4 to 200 , the figures for the NNT as observed in this study imply clinical relevance.

\section{Limitations}

The number of total trials included in this meta-analysis, especially when adopting a random-effects model, may still be considered as small, and this is particularly relevant when interpreting the effect size of individual antidepressants. As with all systematic reviews publication bias is a potential source of error. Three of the studies in this review had a very large effect size and can be considered as outliers. The trimfill method was used to control publication bias. Obviously, this resulted in a reduction of the overall effect size, but this was still statistically significant and clinically relevant. There were no RCTs available for many antidepressants, for example tricyclics, venlafaxine and monoamine oxidase inhibitors. So the results reflect the efficacy of a few and not of all antidepressants.

\section{Implications}

The results of this meta-analysis suggest that antidepressants may be an effective treatment for the negative symptoms of chronic schizophrenia. Among the antidepressants, current data favour ritanserin, trazodone and fluoxetine. There is a need for further studies about side-effects, adherence, cost-effectiveness and effect on quality of life for this combination of antidepressant and antipsychotic medications. It may also be worthwhile to study the response in different subdomains of negative symptoms.

Surendra P. Singh, MD, School of Health and Wellbeing, University of Wolverhampton and Step to Health, Mental Health Directorate, Wolverhampton City Primary Care Trust, Wolverhampton; Vidhi Singh, BSC, MediWare Computer Software Engineering, Wolverhampton; Nilamadhab Kar, MD, DPM, DNB, Software Engineering, Wolverhampton; Nilamadhab Kar, MD, DPM, DNB,
MRCPsych, Mental Health Directorate, Wolverhampton City Primary Care Trust Wolverhampton; Kelvin Chan, PhD, DSC, Research Institute in Healthcare Science and Department of Pharmacy, University of Wolverhampton, Wolverhampton, UK

Correspondence: Surendra P. Singh, Step to Health, Mental Health Directorate, Wolverhampton City Primary Care Trust, Wolverhampton, WV10 9TH, UK. Email: Dr.S.Singh@wlv.ac.uk

First received 25 Apr 2009, final revision 27 Aug 2009, accepted 13 Feb 2010 


\section{Funding}

This study was supported in part by the Quality of Life Research and Development Foundation.

\section{References}

1 Mäkinen J, Miettunen J, Isohanni M, Koponen H. Negative symptoms in schizophrenia: a review. Nord J Psychiatry 2008; 62: 334-41.

$2 \operatorname{Kar} \mathrm{N}$, Jagdisha, Murali N. Efficacy of somatic treatment in treatment resistant schizophrenia. Psychiatry Online 2000 (http://priory.com/psych/ TRS.htm).

3 González-Maeso J, Sealfon SC. Psychedelics and schizophrenia. Trends Neurosci 2009; 32: 225-32.

4 Mulholland C, Lynch G, King DJ, Cooper SJ. A double-blind, placebo-controlled trial of sertraline for depressive symptoms in patients with stable, chronic schizophrenia. J Psychopharmacol 2003; 17: 107-12.

5 Salokangas RK, Saarijärvi S, Taiminen T, Kallioniemi H, Lehto H, Niemi H, et al. Citalopram as an adjuvant in chronic schizophrenia: a double-blind placebocontrolled study. Acta Psychiatr Scand 1996; 94: 175-80.

6 Lee MS, Kim YK, Lee SK, Suh KY. A double-blind study of adjunctive sertraline in haloperidol-stabilized patients with chronic schizophrenia. J Clin Psychopharmacol 1998; 18: 399-403.

7 Poyurovsky M, Pashinian A, Gil-Ad I, Maayan R, Schneidman M, Fuchs C, et al. Olanzapine-induced weight gain in patients with first-episode schizophrenia: a double-blind, placebo-controlled study of fluoxetine addition. Am J Psychiatry 2002; 159: 1058-60.

8 Bustillo JR, Lauriello J, Parker K, Hammond R, Rowland L, Bogenschutz M, et al. Treatment of weight gain with fluoxetine in olanzapine-treated schizophrenic outpatients. Neuropsychopharmacology 2003; 28: 527-9.

9 Friedman Jl, Ocampo R, Elbaz Z, Parrella M, White L, Bowler S, et al. The effect of citalopram adjunctive treatment added to atypical antipsychotic medications for cognitive performance in patients with schizophrenia. J Clin Psychopharmacol 2005; 25: 237-42.

10 Lehmann HE, Ban TA. A placebo-controlled clinical study with trazodone in schizophrenic patients. Psychopharmacol Bull 1977; 13: 11-2.

11 Berk M, Ichim C, Brook S. Efficacy of mirtazapine add on therapy to haloperido in the treatment of the negative symptoms of schizophrenia: a double-blind randomized placebo-controlled study. Int Clin Psychopharmacol 2001; 16: 87-92.

12 Berk M, Gama CS, Sundram S, Hustig H, Koopowitz L, D'Souza R, et al. Mirtazapine add-on therapy in the treatment of schizophrenia with atypical antipsychotics: a double-blind, randomised, placebo-controlled clinical trial. Hum Psychopharmacol 2009; 24: 233-8.

13 Waehrens J, Gerlach J. Antidepressant drugs in anergic schizophrenia. A double-blind cross-over study with maprotiline and placebo. Acta Psychiatr Scand 1980; 61: 438-44.

14 Vartiainen $\mathrm{H}$, Tiihonen J, Putkonen $\mathrm{A}$, Koponen $\mathrm{H}$, Virkkunen $\mathrm{M}$, Hakola $\mathrm{P}$ et al. Citalopram, a selective serotonin reuptake inhibitor, in the treatment of aggression in schizophrenia. Acta Psychiatr Scand 1995; 91: 348-51.

15 Wynchank D, Berk M. Efficacy of nefazodone in the treatment of neuroleptic induced extrapyramidal side effects: a double-blind randomised paralle group placebo-controlled trial. Hum Psychopharmacol 2003; 18: 271-5.

16 Silver $\mathrm{H}$, Nassar A. Fluvoxamine improves negative symptoms in treated chronic schizophrenia: an add-on double-blind, placebo-controlled study. Biol Psychiatry 1992; 31: 698-704.

17 Duinkerke SJ, Botter PA, Jansen AAI, van Dongen PAM, van Haaften AJ, Boom AJ, et al. Ritanserin, a selective 5-HT2/1C antagonist, and negative symptoms in schizophrenia. A placebo-controlled double-blind trial. $\mathrm{Br} \mathrm{J}$ Psychiatry 1993; 163: 451-5.

18 Decina P, Mukherjee S, Bocola V, Saraceni F, Hadjichristos C, Scapicchio P. Adjunctive trazodone in the treatment of negative symptoms of schizophrenia. Hosp Community Psychiatry 1994; 45: 1220-3.

19 Spina E, De Domenico P, Ruello C, Longobardo N, Gitto C, Ancione M, et al. Adjunctive fluoxetine in the treatment of negative symptoms in chronic schizophrenic patients. Int Clin Psychopharmacol 1994; 9: 281-5.

20 Goff DC, Midha KK, Sarid-Segal O, Hubbard JW, Amico E. A placebocontrolled trial of fluoxetine added to neuroleptic in patients with schizophrenia. Psychopharmacology (Berl) 1995; 117: 417-23.

21 Buchanan RW, Kirkpatrick B, Bryant N, Ball P, Breier A. Fluoxetine augmentation of clozapine treatment in patients with schizophrenia. Am J Psychiatry 1996; 153: 1625-7.

22 Hayashi T, Yokota N, Takahashi T, Tawara Y, Nishikawa T, Yano T, et al Benefits of trazodone and mianserin for patients with late-life chronic schizophrenia and tardive dyskinesia: an add-on, double-blind, placebocontrolled study. Int Clin Psychopharmacol 1997; 12: 199-205.
23 Arango C, Kirkpatrick B, Buchanan RW. Fluoxetine as an adjunct to conventional antipsychotic treatment of schizophrenia patients with residual symptoms. J Nerv Ment Dis 2000; 188: 50-3.

24 Silver H, Barash I, Aharon N, Kaplan A, Poyurovsky M. Fluvoxamine augmentation of antipsychotics improves negative symptoms in psychotic chronic schizophrenic patients: a placebo-controlled study. Int Clin Psychopharmacol 2000; 15: 257-61.

25 Schutz G, Berk M. Reboxetine add on therapy to haloperidol in the treatment of schizophrenia: a preliminary double-blind randomized placebo-controlled study. Int Clin Psychopharmacol 2001; 16: 275-8.

26 Shiloh R, Zemishlany Z, Aizenberg D, Valevski A, Bodinger L, Munitz $H$, et al. Mianserin or placebo as adjuncts to typical antipsychotics in resistant schizophrenia. Int Clin Psychopharmacol 2002; 17: 59-64.

27 Poyurovsky M, Isaacs I, Fuchs C, Schneidman M, Faragian S, Weizman R, et al. Attenuation of olanzapine-induced weight gain with reboxetine in patients with schizophrenia: a double-blind, placebo-controlled study. Am J Psychiatry 2003; 160: 297-302.

28 Poyurovsky M, Koren D, Gonopolsky I, Schneidman M, Fuchs C, Weizman A, et al. Effect of the 5-HT2 antagonist mianserin on cognitive dysfunction in chronic schizophrenia patients: an add-on, double-blind placebo-controlled study. Eur Neuropsychopharmacol 2003; 13: 123-8.

29 Zoccali R, Muscatello MR, Cedro C, Neri P, La Torre D, Spina E, et al. The effect of mirtazapine augmentation of clozapine in the treatment of negative symptoms of schizophrenia: a double-blind, placebo-controlled study. Int Clin Psychopharmacol 2004; 19: 71-6.

30 Jockers-Scherübl MC, Bauer A, Godemann F, Reischies FM, Selig F, Schlattmann P. Negative symptoms of schizophrenia are improved by the addition of paroxetine to neuroleptics: a double-blind placebo-controlled study. Int Clin Psychopharmacol 2005; 20: 27-31.

31 Poyurovsky M, Fuchs C, Pashinian A, Levi A, Faragian S, Maayan R, et al. Attenuating effect of reboxetine on appetite and weight gain in olanzapinetreated schizophrenia patients: a double-blind placebo-controlled study. Psychopharmacology (Berl) 2007; 192: 441-8.

32 Akhondzadeh S, Malek-Hosseini M, Ghoreishi A, Raznahan M, Rezazadeh S Effect of ritanserin, a $5 \mathrm{HT} 2 \mathrm{~A} / 2 \mathrm{C}$ antagonist, on negative symptoms of schizophrenia: a double-blind randomized placebo-controlled study. Neuropsychopharmacol Biol Psychiatry 2008; 32: 1879-83.

33 Joffe G, Terevnikov V, Joffe M, Stenberg J, Burkin M, Tiihonen J. Add-on mirtazapine enhances antipsychotic effect of first generation antipsychotics in schizophrenia: a double-blind, randomized, placebo-controlled trial. Schizophr Res 2009; 108: 245-51.

34 World Health Organization. ATC/DDD Index. WHO Collaborating Centre of Drug Statistics Methodology. WHO, 2009.

35 Winkley K, Ismail K, Landau S, Eisler I. Psychological interventions to improve glycaemic control in patients with type 1 diabetes: systematic review and meta-analysis of randomised controlled trials. BMJ 2006; 333: e65.

36 Schünemann HJ, Oxman $A D$, Vist GE, Higgins JP, Deeks JJ, Glasziou P, et al. Interpreting results and drawing conclusions. In Cochrane Handbook for Systematic Reviews of Interventions (Wiley Cochrane Series): 359-84. John Wiley and Sons, 2008.

37 Rummel C, Kissling W, Leucht S. Antidepressants as add-on treatment to antipsychotics for people with schizophrenia and pronounced negative symptoms: a systematic review of randomized trials. Schizophr Res 2005; 80: 85-97.

38 Cohen J. Statistical Power Analysis for the Behavioral Sciences (2nd edn). Lawrence Erlbaum Associates, 1988.

39 Kirsch I, Deacon BJ, Huedo-Medina TB, Scoboria A, Moore TJ, Johnson BT. Initial severity and antidepressant benefits: a meta-analysis of data submitted to the Food and Drug Administration. PLOS Med 2008; 5: e45.

40 Salaffi F, Stancati A, Alberto Silvestri C, Ciapetti A, Grassi W. Minimal clinically important changes in chronic musculoskeletal pain intensity measured on a numerical rating scale. Euro J Pain 2004; 8: 283-91.

41 Rummel C, Kissling W, Leucht S. Antidepressants for the negative symptoms of schizophrenia. Cochrane Database Syst Rev 2006; 3: CD005581.

42 Sepehry AA, Potvin S, Elie R, Stip E. Selective serotonin reuptake inhibitor (SSRI) add-on therapy for the negative symptoms of schizophrenia: a metaanalysis. J Clin Psychiatry 2007; 68: 604-10.

43 Ruiu S, Marchese G, Saba PL, Gessa GL, Pani L. The 5-HT2 antagonist ritanserin blocks dopamine re-uptake in the rat frontal cortex. Mol Psychiatry 2000; 5: 673-7.

44 Arroll B, Macgillivray S, Ogston S, Reid I, Sullivan F, Williams B, et al. Efficacy and tolerability of tricyclic antidepressants and SSRIs compared with placebo for treatment of depression in primary care: a meta-analysis. Ann Fam Med 2005; 3: 449-56.

45 Guaiana G, Barbui C, Hotopf M. Amitriptyline versus other types of pharmacotherapy for depression. Cochrane Database Syst Rev 2003, CD004186. 